Katja Sudec

\title{
IZZIVI USPOSABLJANJA ZA DELO $S$ POSEBNIMI CILJNIMI SKUPINAMI NA PODROČJU KULTURE Projekt AKTIV
}

\section{POVZETEK}

Prispevek na podlagi študije primera projekta AKTIVI obravnava inovativno izobraževanje na področju kulture. Primer vključuje strategijo akcijskega raziskovanja in podpira procesno-razvojno postavljanje ciljev, kar pomeni, da se osredotoča na potrebe udeležencev in izhaja iz dejanskega stanja $v$ družbi. Procesno-razvojno uresničevanje ciljev zahteva raziskovalni pristop in nenehno temeljno spraševanje o vsebinah, ki spodbujajo kritično razmišljanje. V članku opisujemo predavanja in delavnice v okviru projekta ter program simpozija AKTIV. Predstavljamo tudi ciljno skupino in jo primerjamo s populacijo udeležencev. V sklepnem delu so opredeljeni razlogi za uspešno izvedbo projekta ter vpliv na vključene. Interdisciplinarno delo podpira medskupinski dialog, ki ga opažamo kot pozitiven rezultat.

Ključne besede: participativno vodenje, ranljive družbene skupine, interdisciplinarni pristop, timsko delo, ustvarjalne metode

\section{CHALLENGES OF TRAINING FOR WORK WITH SPECIAL TARGET GROUPS IN THE FIELD OF CULTURE: THE AKTIV PROJECT - ABSTRACT}

The paper examines innovative form of education in the field of culture by using the AKTIV project as a case study. The mentioned project includes strategy of action research and employs processand goal-oriented developmental approach, focusing on the needs of the participants, while also taking into account the actual state of the society. Process- and goal-oriented developmental approach is research oriented and includes constant re-examining of contents that promote critical thinking. The paper presents the project's lectures and workshops, and the programme of the AKTIV symposium. Furthermore, the target group is presented and compared to the remaining participants. The conclusion outlines the factors that contributed to successful execution of the project,

1 Projekt je obširno predstavljen v Zborniku za spodbujanje demokratičnega emancipiranega dialoga med ponudniki kulturnih dobrin ter obiskovalci. Dostopno na http://www.so-delujem.com/uploads/page_files/269_ aktivzbornik.pdf (15. 1. 2014).

Mag. akad. slik. Katja Sudec, ksudec@gmail.com 
as well as to its effect on participants. The interdisciplinary work promotes inter-group dialogue, which is considered a positive result.

Keywords: participatory leadership, vulnerable social groups, interdisciplinary approach, teamwork, creative methods

\section{UVOD}

Eno od ključnih vprašanj projekta AKTIV (2013-2014) je bilo, kaj lahko ustvarjalci, muzeji in galerije naredijo za razvoj vključujoče skupnosti. ${ }^{2} \mathrm{~V}$ evropskih državah namreč naraščata ekstremizem in ksenofobičnost, po mnenju Evropske komisije pa »imajo javne institucije dolžnost, da se odzovejo na ta pojav in prispevajo k socialni koheziji. Vključene so tudi kulturne in umetniške institucije, saj omenjena problematika ni le socialna in ekonomska, ampak pogosto simbolična in kulturna.« (European Agenda for Culture, 2014) Kulturne institucije »morajo upoštevati potrebe družbe, ki je kulturno bolj raznolika kot kadarkoli prej« (prav tam). V prispevku bo opisan projekt AKTIV (A kot artikulacija, K kot kreativnost, T kot tim, I kot interdisciplinarnost, V kot vzajemnost), ${ }^{3}$ ki je izhajal iz projekta SOdelujem, saj smo ga zastavili na podlagi njegove evalvacije in pridobljenih izkušenj. Projekt AKTIV se je izvajal v okviru Operativnega programa razvoja človeških virov, razvojne prioritete: »Enakost možnosti in spodbujanje socialne vključenosti«. Vodja in avtorica projekta je tudi avtorica tega članka.

\section{NAMEN IN CILJI PROJEKTA}

Namen projekta je bil krepitev aktivnega vključevanja ranljivih družbenih skupin v kulturno življenje z usposabljanji, ki bi omogočala tudi večjo zaposljivost. Naše delo se je osredotočalo na slepe in slabovidne, a je celoten projekt ponujal priložnost usposabljanja tudi drugim ljudem s posebnimi potrebami ${ }^{4}$ in socialno ranljivim skupinam.

Projekt je imel naslednje cilje:

- $\quad$ usposobiti slepe in slabovidne ter druge osebe s posebnimi potrebami (na primer gibalno ovirane) in kulturne delavce za projektni menedžment v kulturnih institucijah (muzeji in galerije);

- $\quad$ usposobiti kulturne delavce v kulturnih institucijah in samostojne kulturne delavce za delo s slepimi in slabovidnimi;

2 Skupina za odprto metodo usklajevanja za promocijo kulturne raznolikosti (OMU) in medkulturnega dialoga Evropske komisije iz Bruslja je projekt sodelujem (Skupaj integrativno na področju kulture) ocenila kot primer dobre prakse. Ta projekt je bil izhodišče za nastanek projekta AKTIV (http://ec.europa.eu/culture/ library/index_en.htm).

3 Prijavitelj projekta AKTIV je bilo društvo ŠKUC, finančno ga je podprlo ministrstvo za kulturo in ga delno financirala Evropska unija, in sicer iz Evropskega socialnega sklada.

$4 \mathrm{~V}$ projektnem delu je bilo veliko razprav o uporabi poimenovanj invalid in hendikepirana oseba. Uporabljali smo naslednje pojme: osebe s posebnimi potrebami, osebe z osebno okoliščino oviranosti, Evgen Bavčar uporablja poimenovanje oseba z odvzeto svobodo. V poročilih smo se prilagodili razpisni dokumentaciji, ki je uporabljala izraza invalid, invalidna oseba. 
- $\quad$ usposobiti slepe in slabovidne ter gibalno ovirane za delo v podpornih programih (animator, evalvator) kulturnih institucij;

- razviti nova gradiva in metode (za prenos kulturnih dobrin) za slepe in slabovidne in druge ciljne skupine;

- $\quad$ krepiti možnosti za zaposljivost ljudi s posebnimi potrebami (ranljivih družbenih skupin, zlasti slepih in slabovidnih) v kulturnih institucijah;

- prenašati dobre prakse iz tujine in jih prilagoditi lokalnim potrebam.

Med vključenimi je bila primarna skupina slepih in slabovidnih, saj je ta izključena iz likovne in vizualne umetnosti. Poleg slepih in slabovidnih pa so bile vključene tudi druge ranljive družbene skupine. Usposobljeni posamezniki (pripadniki ranljivih družbenih skupin in kulturni delavci) naj bi s svojim znanjem iz projektnega menedžmenta in poznavanjem metod dela vodili dopolnilne projektne predloge v posamezni kulturni instituciji. Poudarek je bil na interdisciplinarnosti in kreativnih načinih razmišljanja za nove artikulacije in posredovanje kulturnih vsebin. Rezultate so delovne skupine promovirale na skupni spletni strani. Ob zaključku projekta je bil ustanovljen Zavod UPS, Ustvarjalna pisarna sodelujem. Poleg tega ustanavljamo tudi Klub Ljubiteljev Umetnosti: Asistenca (KUL:A), ki bo osebam z oviranostjo ponujal asistenco za udeležbo na kulturnih prireditvah.

\section{AKCIJSKO RAZISKOVANIE IN INTERDISCIPLINARNOST}

Projekt smo razvijali z metodo akcijskega raziskovanja (Costello, 2011; Stringer, 2013). Pred prijavo na razpis je bilo izvedeno anketno povpraševanje med kulturnimi delavci. Tako smo že na začetku načrtovanja vzpostavili procesno-razvojni način dela. Proučili smo razpisne pogoje ter jih primerjali z rezultati in aktualnimi potrebami okolja. Sledili smo načelom kakovosti načrtovanja neformalnega izobraževanja (prim. Možina, 2013) in vodenja kot procesa, s katerim nekdo motivira druge (posameznike in skupine), da uspešno opravljajo delo in dosegajo cilje. Pri tem organizira, usmerja in preverja tudi različne pogoje dela, da se tako delo tudi lahko opravlja. Proces vodenja ni enosmeren, od voditelja $\mathrm{k}$ vodenim, temveč gre za participativno vodenje, ki omogoča prepletanje vodenih in voditeljev ob določeni odgovornosti za končni izid (prav tam, str. 38).

Delo smo organizirali v skladu s poznavanjem skupinskega dela. Poseben poudarek smo namenili timskemu delu. V delovno ekipo so bile vključene tudi slepe osebe, ki so bile odgovorne za stike z javnostmi, predvsem za informiranje slepih in slabovidnih. V oblikovanih delovnih skupinah je vsaj ena slepa oseba sodelovala kot koordinator in/ali strokovni delavec, pripadniki ciljne skupine pa so bili tudi med predavatelji.

Projekt je spodbujal interdisciplinaren pristop. Upoštevali smo zakonitosti vseh vključenih disciplin in skupin. Ponudili smo znanja o specifičnem delu v muzejih in galerijah (animacija, evalvacija ponujenih programov) s poudarkom na njegovem ustvarjalnem podajanju, in sicer tako, da bodo vsebine dostopne za specifične ciljne skupine. Ker je umetniški jezik univerzalen in daje možnost veččutnega dojemanja, je 
bil večji del projekta namenjen razvoju strategij (gradiv in metod) v korist raznolikim prejemnikom umetnosti s poudarkom na razvijanju veččutnega pristopa, ki je lasten slepim in slabovidnim.

Prizadevali smo si za enakomerno razporeditev usposabljanj na strukturno organizacijskem področju (kulturni menedžment, kulturna politika, prakse dela na področju kulture in praktično delo). Projekt je spodbujal pridobivanje znanja iz galerijskega posredovanja (pedagogike, animacije, mediacije) in poudarjal razvoj novih metod.

\section{PROGRAM IN POTEK USPOSABLJANJ}

Usposabljanja $^{5}$ (program izobraževanja) smo razdelili na dva dela (delovne skupine in simpozij), vsebinsko pa je obsegal naslednje sklope (module):

- projektni menedžment s poudarkom na kulturnem menedžmentu (ta sklop je časovno potekal najprej),

- uveljavljene prakse dela z ranljivimi družbenimi skupinami,

- ustvarjalne metode dela z ranljivimi družbenimi skupinami, razvoj gradiva in metod (v galerijskem in muzejskem prostoru).

Pretežni del projekta je bil namenjen uporabi umetniškega jezika za razvoj gradiv in metod za usposabljanja na področju kulture, predvsem za skupine slepih in slabovidnih, zato smo izhajali iz zakonitosti sveta slepih in slabovidnih ter jih prenašali tudi na področja drugih ciljnih skupin z namenom, da bi spodbujali razvoj drugačnega dojemanja kulturnih dobrin in sveta nasploh. V ospredje smo postavljali dvoje: ustvarjalno podajanja ter skrb za dostopnost in informiranost marginaliziranih skupin.

\section{SIMPOZI]}

Pred izvedbo programov delovnih skupin (AKTIV I, II in III) smo pripravili mednarodni simpozij, namenjen strokovni publiki in ciljnim skupinam. Zajemal je teoretični pregled stanja doma in po svetu ter razvoj in raziskovanje novih metod dela. Potekal je v Mestnem muzeju Ljubljana pod častnim pokroviteljstvom varuhinje človekovih pravic RS Vlaste Nussdorfer. Koncept sem pripravila avtorica članka s podporo doc. Claudie Hummel, Katarina Majerhold pa je kot ena od področnih urednic Časopisa za kritiko znanosti zagotovila prostor za objavo člankov.

Namen simpozija je bil spodbujanje demokratičnega emancipiranega dialoga med ponudniki kulturnih dobrin in obiskovalci. V okviru simpozija smo poskušali najti odgovor na vprašanji, kaj lahko ustvarjalci, muzeji in galerije naredijo za družbo oziroma obiskovalca ter kako naj to poteka, s kom in za koga.

Program simpozija je bil zasnovan na vsebinskih osnovah dela z občinstvom v galerijskem in muzejskem prostoru, da bi omogočili uvid v celotno področje galerijske pedagogike.

$5 \quad \mathrm{~V}$ projektu smo uporabljali izraz usposabljanje (training). 
Uvodna predavanja tujih in domačih predavateljev so bila zato namenjena osnovam galerijske pedagogike.

Udeležencem smo želeli dati osnovno teoretično podlago za delo v galerijah in muzejih. Želeli smo tudi spodbuditi medsebojno povezovanje med strokovnimi delavci, predavatelji in udeleženci. Cilji so bili uresničeni, saj so udeleženci v evalvaciji izrazili zadovoljstvo $\mathrm{z}$ načinom organizacije in pridobljenim znanjem. Tudi izhodišče »od teorije k praksi« in nato $\mathrm{k}$ interdisciplinarni predstavitvi dela s slepimi in slabovidnimi je bilo pozitivno ocenjeno. Eden od udeležencev je napisal:

»Pionirsko delo, ki je bilo dolgo časa prezrto oziroma odmaknjeno.« (anonimni udeleženec simpozija, februar 2014)

Predavanja tujih predavateljev so domačim strokovnjakom prinesla nekatere informacije s skupnega področja dela, ki pa poteka na drugačen način. Postalo je jasno, da je galerijski pedagog (oziroma galerijski pedagog kot umetnik) strokovno profiliran poklic, ki se pri nas s takimi projekti šele vzpostavlja.

Simpozij se je sklenil z diskusijskimi skupinami, ki jih je vodil domači strokovnjak. V njih smo obravnavali naslednje vsebine:

- $\quad$ strukturna vez šole in kulturne ustanove: delo z otroki in mladino ter specifične potrebe;

- $\quad$ kdo je drugi;

- $\quad$ sistemska vprašanja povezovanja kulturnih institucij navzven in spodbujanje aktivnosti ranljivih skupin.

Vtis s simpozija predstavi zapis enega od udeležencev:

»V̌̌eč mi je bila debata, kjer smo odkrili trenutne razmere v muzejih, galerijah, ki želijo odpreti vrata ranljivim skupinam, vendar vsi govorijo o glavnem problemu: ni dovolj denarja. Zato mi je bila všeč replika, da se moramo sami potruditi in sodelovati med strokami, država nam ne bo vedno (uspela) pomagati. Sicer tako delo (samoiniciativa, sodelovanje) zahteva nas celega, to ni služba od $7 \mathrm{~h}$ do $15 \mathrm{~h}$, temveč skoraj način življenja.« (anonimni udeleženec simpozija, februar 2014)

\section{DELOVNE SKUPINE - AKTIV I, II IN III}

Po simpoziju se je začelo praktično delo v delovnih skupinah, ki smo jih vzpostavili v Ljubljani, Mariboru in na dvojezičnem območju Ljutomera in Razkrižja. Kot mentorji so sodelovali strokovnjaki s področja kulture in šolstva.

Delovno skupino AKTIV I so vodili R. Kroflič, J. Markota, D. Štirn in P. Štirn Janota, njeno delo pa je usmerjal naslov Razvoj likovnih ustvarjalnic poustvarjanja $v$ umetniških muzejih. Pretežno je delovala v Ljutomeru, kjer je sodelovala z Galerijo Ante Trstenjak in 
Gimnazijo Franca Miklošiča Ljutomer ter okoliškimi vrtci (vrtci Razkrižje, Ljutomer in Stročja vas), kjer imajo nekaj dvojezičnih otrok.

Delovna skupina AKTIV I je skozi usposabljanje preverjala model izkustvenega učenja, v okviru katerega je udeležence po metodi petih korakov, ki vključuje senzibilizacijo, informacijo, dialoškost, ustvarjalnost in družbeni angažma, vodila $\mathrm{k}$ spoznavanju pedagoških predpostavk, ki so pogoj za emancipatoričen stik z umetniškim doživetjem. Prvi del usposabljanja je bil namenjen senzibilizaciji pomena in vloge umetnosti v vzgojno-izobraževalnem procesu. Drugi del sta sestavljala predstavitev teoretičnih konceptov in aktivni razmislek udeležencev, kako pri najmlajših ustvariti prostor za umetniška doživetja in kako premisliti vlogo pedagoškega delavca onkraj paternalističnega pedagoškega mita o nujni razlagalni pomoči vzgajani osebi/gledalcu. V tem delu so udeleženci tudi pripravili svoje načrte za dejavnosti z otroki, vzporedno pa je ekipa AKTIV I raziskovala in pripravljala metode pedagoškega vodenja otrok po galeriji v skladu z načeli emancipiranega gledalca. $V$ tretjem delu sta sledila praktično vodenje otrok po galeriji in evalvacija. ${ }^{6}$

AKTIV II je deloval v Ljubljani pod vodstvom stalne ekipe projekta, to so bili A. Krepel-Velimirović, K. Modic, K. Majerhold, K. Bajec, B. Vogrinčič, A. Čefarin, M. Mikulin, A. Surla in K. Sudec. Pod naslovom Občutenje prostora: razvoj performativnih reakcij kot metoda raziskovanja dostopnosti in spoznavanja prostora muzejskih prostorov ter razstavnih del so se odvile praktične delavnice in predavanja v sodelovanju z Galerijo Cankarjevega doma (v času Kulturnega bazarja), Malo galerijo Univerzitetnega kliničnega centra Ljubljana in Knjižnico Tolmin.

Delovna skupina je na usposabljanjih spoznavala metodologijo performativnih reakcij umetniškega posredovanja in na razvojnih delavnicah ob praktičnih primerih razvijala lastne programe, ki jih je nato predstavila v izbranih kulturnih institucijah. V tem sklopu smo glavno pozornost namenili avtobiografskemu snovanju kot eni od metod umetniškega posredovanja in konceptualizaciji performativnih reakcij. Vzporedno je delovna skupina raziskovala metode in pripravila lastne rešitve dostopnosti galerijskih in muzejskih prostorov.

Zadnji, tretji sklop usposabljanj pa se je osredotočal na spoznavanje podpornih dejavnosti in aktivno participacijo udeležencev pri njihovi zasnovi in izvedbi, in sicer: sodelovanje pri postavitvi razstave $\mathrm{v}$ galerijskem prostoru; razvoj PR-strategij in odnosov $\mathrm{z}$ javnostjo; krepitev veščine javnega nastopanja ob javnih predstavitvah dela skupine. ${ }^{7}$

V delovni skupini AKTIV III, ki so jo sestavljali A. Kermauner, B. Strnad, M. Licardo, J. Herzog, D. Lozinšek s strokovnim svetovanjem dddr. E. Bavčarja in doc. dr. T. Zupančiča, so raziskovali pod naslovom Ustvarjalne metode dela z ranljivimi družbenimi skupinami - slepimi in slabovidnimi/razvoj gradiva in metod. Sodelovali sta Umetnostna galerija Maribor in Pedagoška fakulteta Univerze v Mariboru. V nasprotju z drugima

6 Koncept AKTIV I (glej Sudec, 2013).

7 Koncept AKTIV II (glej Sudec, 2013). 
dvema skupinama so tukaj kot udeleženci prevladovali študenti tretjega letnika likovne pedagogike Pedagoške fakultete Univerze v Mariboru s slepimi kolegi iz Društva slepih in slabovidnih Maribor.

Delovna skupina je $\mathrm{v}$ okviru usposabljanj eksperimentirala $\mathrm{z}$ ustvarjalnimi metodami dela in v sklopu razvojnih delavnic na praktičnih primerih razvijala metode, ki jih je predstavila v izbranih kulturnih ustanovah. V prvem sklopu so glavno pozornost namenili doživljanju likovne umetnosti z vidika slepih in slabovidnih oseb. V drugem sklopu je delovna skupina raziskovala ustvarjalne metode dela s slepimi in slabovidnimi osebami. Udeleženci so na praktičnih rešitvah preizkušali učinkovitost metod (spoznavanje izdelave tipank, spoznavanje metod pri predstavljanju umetniških del na ploskvi slepim in slabovidnim osebam) ter pripravili lastne rešitve za dostopnost galerijskih in muzejskih prostorov. Tretji sklop usposabljanj pa se je osredotočal na spoznavanje in aktivno participacijo udeležencev pri zasnovi in izvedbi, kar je pomenilo sodelovanje pri vodstvih po razstavi 60 !Panorama v Umetnostni galeriji Maribor in pri postavitvi razstave, prilagojene slepim in slabovidnim osebam, $\mathrm{v}$ galerijskem prostoru ter razvijanju idej ob delu z metodami. ${ }^{8}$

Delovne skupine so interdisciplinarno razvijale nove pristope in metodologije dela, $\mathrm{v}$ sklepni fazi je skupinam strokovno svetoval dddr. Evgen Bavčar. Na koncu smo v okviru vzpostavljenih delovnih skupin razvite strategije in projektne predloge ponudili različnim skupinam, na podlagi česar so delovne skupine preverjale učinkovitost razvitih metodologij.

\section{O UDELEŽENCIH}

Udeleženci simpozija, vseh je bilo 146, so bili z različnih institucij in različnih profilov (študenti pedagoške in filozofske fakultete, kulturni delavci, pedagogi, zgodovinarji, uredniki časopisov za senzorno ovirane, arhitekti, gledališčniki, profesorji različnih fakultet, učitelji tiflopedagogike, osebje iz društev in zavodov slepih in slabovidnih). V usposabljanja pa so se lahko vključili tako pripadniki ranljivih skupin kot tudi drugi (slepi in slabovidni, etnične manjšine, strokovni delavci s področja kulture, vzgoje in izobraževanja, socialnega dela, psihologije). Tak način odprtosti podajanja znanj s posameznih področij tudi (ne)ranljivim upravičujejo naši cilji, ki opredeljujejo usposobljenost ranljivih na področju kulture kot tudi delo z ranljivimi skupinami. Ob tem je jasno, da se moramo za delo z raznoliko publiko usposobiti vsi, če želimo skupaj dobro in strpno delovati. S tem povečujemo medsebojno razumevanje, nadgrajujemo vsebine in krepimo inovativno raziskovanje, možnosti dela v interdisciplinarnem, pa tudi »medsocialnem « kontekstu. Z izrazom »medsocialno« opredeljujemo timsko sodelovanje raznolikih družbenih skupin.

Med udeleženci izobraževalnih programov in drugih oblik je bilo 148 takih, ki so vztrajali od začetka do konca. Že na začetku pa je vztrajnosti zmanjkalo tistim, ki so začeli obiskovati usposabljanja iz projektnega menedžmenta. Njihov velik upad se je pokazal

8 Koncept AKTIV III (glej Sudec, 2013). 
po izvedbi simpozija, ko se je za praktično delo v delovni skupini AKTIV II odločila le peščica. V drugih dveh skupinah, kamor so se novi udeleženci priključili po obisku simpozija, pa je, ravno obratno, število naraslo. To dinamiko pripisujemo specifični obliki neformalnega izobraževanja. Po tem je mogoče sklepati, da je primernejše krajše časovno obdobje, saj se aktivnost udeležencev po šestih mesecih zmanjša. V primerjavi s projektom SOdelujem, kjer so usposabljanja za eno skupino trajala največ šest mescev, lahko temu pritrdimo, saj je bila takrat aktivnost udeleženih ob izteku programa velika.

Po profilih udeležencev so bile najpogosteje zastopane naslednje stroke: muzealec, tiflopedagog, umetnostni zgodovinar, socialni delavec, likovni pedagog. Tem sledijo muzejski pedagog, galerist kustos, kipar, slikar, zgodovinar, menedžer. Nato srečamo še pestro paleto udeležencev iz drugih strok. Teh je bilo v primerjavi s prvimi več, kar priča o širokem naboru znanja, združenega v projektu. To so bili: arhitekt, glasbenik, kulturni delavec v gledališču, sociolog, antropolog, socialni antropolog, filozof, teolog, informacijski tehnolog, organizator projektov, ekonomist, komparativist, rusist, primerjalni književnik in politolog.

\section{SKLEP}

Pri razvoju projekta smo sledili načelom procesnega načrtovanja in interaktivnega modela, kot ga je za načrtovanje izobraževanja razvila Caffarella (Caffarella in Ratcliff Daffron, 2013; prim. Kroflič, 1992). Cilji so bili skrbno zasledovani skozi celotno obdobje projekta in so se glede na procesno-razvojno delo dopolnjevali. Udeleženci so bili motivirani z natančno opredeljenimi cilji in možnostjo vpliva na izvedbo. Po evalvaciji smo ugotovili, da so bile izbrane oblike izobraževanja (uvodne delavnice, simpozij, tri delovne skupine) optimalno uporabljene. Projekt je omogočil nagovarjanje novega občinstva in odpiranje novih obzorij »tradicionalni « publiki ter spodbudil razvoj novega tipa kulturnega delavca, ki ga kulturne institucije potrebujejo zato, da bi (celovito) nagovarjale različne ciljne skupine.

Človek kot ontološko bitje hrepeni po celoviti obravnavi in celostnem delovanju. Prav za tako celovitost smo si prizadevali s projektom AKTIV, ki vključene nagovarja k skupnemu delovanju in razvoju vključujoče skupnosti. Projekt je v naš prostor uvedel novosti na področju načrtovanja in medsebojnega povezovanja umetnikov, znanstvenikov in ciljnih skupin s posebnimi potrebami ter postavil tudi izhodišče za novo raziskovanje na področju neformalnega izobraževanja. Naša raziskava je slonela na metodi akcijskega raziskovanja, ki bi jo lahko v nadaljevanju dopolnili še z drugimi raziskovalnimi metodami.

\section{LITERATURA}

Burnham, R. in Kai-Kee, E. (2011). Teaching in the Art Museum. Los Angeles: Paul Getty Museum.

Caffarella S., R. in Ratcliff Daffron, S. (2013). Planning Programs for Adult Learners. San Francisco: Jossey-Bass.

European Agenda for Culture (2014). Good Practice Report on the Cultural and Creative Sectors" Export and Internationalisation Support Strategies. Pridobljeno s http://ec.europa.eu/culture/library/index_en.htm; http://ec.europa.eu/culture/library/reports/report-cultural-creative_en.pdf. 
European Agenda for Culture (2014). Report on the Role of Public Arts and Cultural Institutions in the Promotion of Cultural Diversity and Intercultural Dialogue. Pridobljeno s http://ec.europa.eu/ culture/library/reports/201405-omc-diversity-dialogue-sum_en.pdf.

Kroflič, R. (2014). Emancipacija skozi umetniško doživetje in pomen hendikepa kot instance drug(ačn) osti. Časopis za kritiko znanosti, domišljijo in novo antropologijo, 42(255), 117-127.

Kroflič, R. (1992). Teoretski pristopi k načrtovanju in prenovi kurikuluma. Ljubljana: Center za razvoj univerze.

Majerhold, K. (ur.). (2014). Zbornik za spodbujanje demokratičnega emancipiranega dialoga med ponudniki kulturnih dobrin ter obiskovalci. Ljubljana: Društvo ŠKUC, Galerija ŠKUC.

Možina, T. (ur.) (2013). Kazalniki kakovosti izobraževanja odraslih. Ljubljana: Andragoški center Slovenije. Pridobljeno s http://www.so-delujem.com/uploads/page_files/269_aktivzbornik.pdf.

Stringer, E. T. (2013). Action Research. London: Sage.

Sudec, K. (2013). Projektna prijava AKTIV. Koncepti delovnih skupin in rezultati projekta AKTIV. Pridobljeno s http://www.so-delujem.com/projekt-sodelujem/.

Taylor, E. W. in McKinley Parrish, M. (ur.). (2010). Adult Education in Cultural Institutions: Aquariums, Libraries, Museums, Parks, and Zoos. San Francisco: Jossey-Bass. 